\title{
Psychological impact of COVID -19 pandemic on frontline health care workers in Bangladesh: A cross-sectional study
}

\author{
Mohammad Shamsul Ahsan, Suman Ahmed, Rubaiya Khan, Md Mahbubul Hasan, Ananya Kar, \\ Humayra Shahjahan, Fahmida Ferdous, Murin Hossain, Md Kamrul Hossain
}

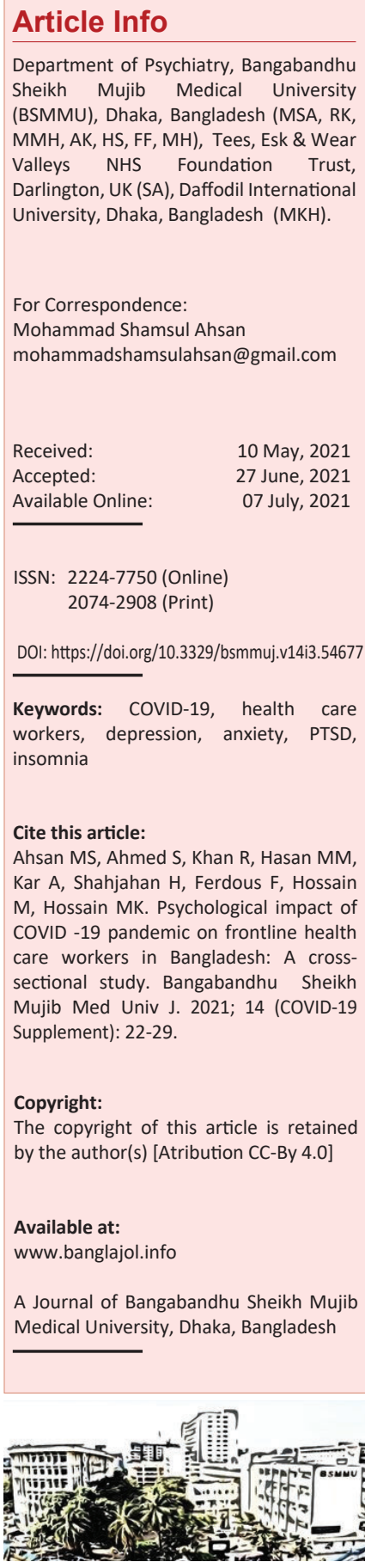

\begin{abstract}
This study aimed to estimate the prevalence of depression, anxiety, post-traumatic stress disorder, and insomnia symptoms among frontline health workers during the corona virus disease 19 (COVID-19) pandemic in Bangladesh and to compare these between medical and allied health workers. We conducted a cross-sectional survey between June and August 2020. A total of 479 health care professionals participated in the study. Anxiety and depression were measured using Patient Health Questionnaire-4 (PHQ-4), post-traumatic stress disorder (PTSD) was measured by primary care post-traumatic stress disorder score (PC-PTSD score), and insomnia was measured by Insomnia Severity Index (ISI). We performed logistic regression to assess risk factors associated with psychological symptoms. Overall, prevalence of anxiety, depression, PTSD and insomnia symptoms were $17.6 \%, 15.5 \%, 7.6 \%$ and 5.9\%, respectively. Compared to allied health workers, doctors had significantly higher prevalence of symptoms of anxiety: doctor versus allied health care worker; $21.1 \%$ vs $06 \%,(\mathrm{OR}=4.19 ; 95 \%$ $\mathrm{CI}=1.88-9.35 ; \mathrm{p}<0.001)$; depression: $18 \%$ vs 6.8\%, $(\mathrm{OR}=2.99 ; 95 \% \mathrm{CI}=1.40-6.42 ; \mathrm{p} 0.005)$; PTSD: $9.4 \%$ vs $1.7 \%,(\mathrm{OR}=5.96 ; 95 \% \mathrm{CI}=1.41-25.11$; p 0.015) and insomnia: $7.4 \%$ vs $0.9 \%,(\mathrm{OR}=$ 9.22; 95\% CI= 1.24-68.4; p 0.03),respectively. The logistic regression analysis showed pre-existing medical illness as a predictor of anxiety $(\mathrm{OR}=2.85 ; 95 \% \mathrm{CI}=1.71-4.76 ; \mathrm{p}<0.001)$ and depressive symptoms $(\mathrm{OR}=2.29 ; 95 \% \mathrm{CI}=1.39-3.77 ; \mathrm{p} 0.001)$. Working more than $6(\operatorname{six})$ weeks in COVID-19 dedicated hospitals was significantly associated with PSTD symptoms $(\mathrm{OR}=2.83 ; 95 \% \mathrm{CI}=1.35-5.93 ; \mathrm{p} 0.006)$ and insomnia $(\mathrm{OR}=2.63 ; 95 \% \mathrm{CI}=1.15-6.02 ; \mathrm{p} 0.022)$. Our study demonstrated a high prevalence of symptoms of depression, anxiety, PTSD, and insomnia among Bangladeshi frontline health workers during the COVID-19 pandemic.
\end{abstract}

\section{Introduction}

The novel coronavirus disease 19 (COVID-19) outbreak started in early December 2019 in Wuhan, Hubei province, China. ${ }^{1}$ Since then the cases have spread widely over the last year with a rapidly increasing number of deaths, affecting almost every country across the world hence World Health Organization (WHO) has declared a global pandemic. ${ }^{2}$

In addition to the chance of directly contracting infection due to close contact with patients, their careers, and/ or potentially infectious asymptomatic co-workers during the COVID-19 pandemic, healthcare professionals are also under huge stress and mental health risks, as was the case reported during the previous SARS epidemic. ${ }^{3.4}$ Frontline health care workers who are providing services to the COVID-19 patients are at increased risks of contracting illness, transmitting infection back home to the elderly relatives. Besides, long working hours with personal protective equipment (PPE), infection of some front liners put pressure on the unaffected front liners. 5,6

Several recent studies have highlighted the significant psychological effect of health workers during the COVID-19 outbreak in other countries. ${ }^{7,8}$ There is a burning need for appropriate measures to maintain the mental health and well-being of healthcare professionals in such stressful situations., ${ }^{9,10}$ Despite the clear emphasis on the mental 
health needs of health care professionals during the campaign against COVID-19, a very limited number of researches on the potential mental health problems in the health care workforce during this ongoing surge of COVID-19 patients in Bangladesh has been reported. This is particularly necessary in the Bangladeshi cultural context incorporating the public attitude and stigma towards COVID-19 cases and their care giver. Our goal was to provide an updated insight and evidence into the mental health needs of frontline health care professionals during a pandemic or national disaster situation in the Bangladeshi cultural context to advocate for supportive programming and policy review. Hopefully, this result will help a broader understanding of mental health issues of front-line health care workers dealing with the second wave of the COVID-19 pandemic.

The primary objective of our study was to estimate the prevalence of mental health-related problems specifically depression, anxiety, insomnia, and post-traumatic stress symptoms among frontline health workers during the COVID-19 pandemic in Bangladesh. Our Secondary objectives were: (1) to identify significant predictors of developing these mental health symptoms. (2) to ascertain any difference of mental health-related COVID-19 impacts between medical doctors and allied health professionals i.e. nurses, medical technicians, and support workers.

\section{Materials and methods}

\section{Study design and participants:}

We conducted a cross-sectional survey among front-line health professionals between $3^{\text {rd }}$ June and $31^{\text {st }}$ August 2020 during the COVID-19 pandemic in Bangladesh. We included the frontline health workers who were 18 years of age or older, able to provide informed verbal consent, and able to participate in a telephone interview at the time of the survey. We excluded those who had pre-existing mental health conditions (neurotic or psychotic disorders) and insomnia before the outbreak of COVID-19. The data collection involved two steps. In the first step, we used social media platforms, organized a series of webinars, and used the social networks of the research team to reach out to the maximum target population. We also requested recipients to disseminate the survey information among their relevant colleagues. We developed a Google form containing participant information leaflets (English and Bengali), a consent form (English and Bengali), and a sociodemographic questionnaire that was disseminated in these platforms inviting health care professionals to voluntarily participate in the study. In the second step, we contacted those who completed the consent form and sociodemographic questionnaire for the telephone interview. We double-checked the information participants had provided and rectified any discrepancy in the information provided in Google form. We recruited participants from all levels of health care facilities (primary, secondary and tertiary) dealing with COVID19 patients in different parts of Bangladesh.

\section{Sample size:}

Our calculated sample size was 320 with assumption of $20-25 \%$ prevalence of psychological morbidities based on the findings of previous studies done on COVID-19 (alpha 0.05 and power at $80 \%) .{ }^{8,9}$ Since the magnitude of COVID-19 increased and increased number of hospitals were made COVID dedicated hospitals we finally enrolled 479 front liners in this study.

\section{Measures:}

\section{a)Socio-demographicE work-related characteristics:}

We collected data using the Google Form questionnaire (English and Bengali) later verified by the interviewer during telephone interview which included the following: Age, Sex, Profession (medical doctor/allied health professional), educational attainment (undergraduate/ graduate/ postgraduate), years of experience, marital status, living circumstances (urban/semi-urban/rural; with family/without family), Pre-existing medical conditions (asthma/COPD, diabetes, neurological disease/stroke, cardiovascular disease, immuneuncompromised for any reasons, others), lifestyle (sedentary/ moderately active/ hard labor), smoking habit, work setting, placement and duration of duty in Covid dedicated hospitals.

\section{b)Mental health symptoms:}

We asked the participants whether they had insomnia or psychiatric disorders before the COVID-19 pandemic. We excluded those who had positive history from the study.

Anxiety and depression: We assessed participants anxiety and depression with a 4-item Patient Health Questionnaire-4 $(\mathrm{PHQ}-4)^{11}$ which is an ultra-brief self-report questionnaire. A cut-off $\geq 3$ in first 2 questions indicate a case of anxiety and that of last 2 questions recommend to depression respectively.

Post-Traumatic Stress Disorder (PTSD): For PTSD, a 4-item screening questionnaire, was used. ${ }^{12}$ PC-PTSD should be considered "positive" if a patient answers "yes" to any 3 items.

Insomnia: A 7-item self-reported questionnaire, Insomnia Severity Index (ISI)was used to assessthe nature, severity, and impact of insomnia. ${ }^{13} \mathrm{An}$ ISI total score $\geq 8$ indicates that insomnia is present.

\section{Statistical analysis plan:}

We collected socio-demographic and work-related data (independent variables) online using Google form then cross-checked during the telephone interview when mental health-related data collected using paper-based validated tools (described above). The data were inputted and coded from the Google Forms and paper-based tools to the Microsoft Excel spreadsheet. The data were then exported to Statistical Package for Social Sciences (SPSS) Statistics for Windows, Version 20.0 (IBMCorp., USA, 2011) for statistical analysis.

The Pearson Chi-square tests were used to compare group differences (medical doctor vs allied health professionals) of categorical variables (Table 1). To determine the association between categorical independent variables and categorical 
dependent variables, we also used the Pearson Chi-square test (Table 2A and 2B). We performed logistic regression analyses to explore the independent influence on insomnia, anxiety, depression, and PTSD symptoms (Table 3). We calculated the odds ratio with a 95\% confidence interval (CI). We tested all hypotheses at a significance level at a p-value $\leq 0.05$.

\section{Results}

A total of 574 Front-Line Health Professionals (FHP) had responded (medical doctors, and allied health professionals) through Google Form. Of them, 63 were excluded (either withdrawn consent while telephone interview or didn't respond to calls or text messages). From the remaining 511 participants, 29 had a pre-existing mental illness; 03 had a history of substance abuse and were excluded. Finally, a total of 479 FHP was included and 366 (76\%) were medical doctors and $113(24 \%)$ were allied health professionals (nurses, ward support workers, lab technicians). Most of them were male $67 \%$ (doctors vs allied, $75.1 \%$ vs $40.7 \%$ ), young age ( $\leq 35$ years) $79.5 \%$, married $78.1 \%$ (doctors vs allied, $80.9 \%$ vs $69 \%$ ), graduate $73.3 \%$ (doctors vs allied, $80.3 \%$ vs $50.4 \%$ ), and they were staying with family $69.1 \%$ (doctors vs allied, $80.9 \%$ vs $69 \%$ ). They were mostly from urban background $85 \%$ (doctors vs allied, $81.7 \%$ vs $95.6 \%$ ) and non-smokers $89.6 \%$ (doctors vs allied, $88.5 \%$ vs $92.9 \%$ ). They were mostly working at tertiary care setting $80.8 \%$ ((doctors vs allied, $77 \%$ vs $92.9 \%$ ) and in Covid19 dedicated hospitals 78.5\% ((doctors vs allied, 74\% vs $92.9 \%$ ). $47 \%$ (doctors vs allied, $51.4 \%$ vs $32.7 \%$ ) of them had $6-12$ years experience and only $25.3 \%$ (doctors vs allied, $28.7 \%$ vs $14.2 \%$ ) of them had a pre-existing medical condition (table-I).

\section{Table-I}

Socio-demographic characteristics in medical doctors versus allied health professionals:

\begin{tabular}{|c|c|c|c|c|c|}
\hline \multirow[t]{2}{*}{ Sample Characteristics } & \multirow[b]{2}{*}{$\begin{array}{l}\text { Variables } \\
\text { Subcategory }\end{array}$} & \multicolumn{2}{|c|}{ Profession $n=479$} & \multirow{2}{*}{$\begin{array}{l}\text { Total } \\
\mathrm{n}(\%)\end{array}$} & \multirow{2}{*}{$\begin{array}{r}\text { P-value } \\
\mathrm{X}^{2} \text { test }\end{array}$} \\
\hline & & $\begin{array}{l}\text { Allied Health } \\
\text { professional } \\
n=113 n(\%)\end{array}$ & $\begin{array}{c}\text { Medical } \\
\text { Doctor } \\
\mathrm{n}=366 \mathrm{n}(\%)\end{array}$ & & \\
\hline \multirow[t]{3}{*}{ Age (years) } & $<=35$ & $91(80.5)$ & $290(79.2)$ & $381(79.5)$ & 0.401 \\
\hline & $36-45$ & $19(16.8)$ & $55(15.1))$ & $74(15.4)$ & \\
\hline & $>45$ & $3(2.7)$ & $21(5.7)$ & $24(5.1)$ & \\
\hline \multirow[t]{2}{*}{ Sex } & Female & $67(59.3)$ & $91(24.9)$ & $158(33.0)$ & $<0.001$ \\
\hline & Male & $46(40.7)$ & $275(75.1)$ & $321(67.0)$ & \\
\hline \multirow[t]{3}{*}{ Educational Qualifications } & Undergraduate & $54(47.8)$ & $0(0.0)$ & $54(11.3)$ & $<0.001$ \\
\hline & Graduate & $57(50.4)$ & $294(80.3)$ & $351(73.3)$ & \\
\hline & Postgraduate & $2(1.8)$ & $72(19.7)$ & $74(15.4)$ & \\
\hline \multirow[t]{3}{*}{ Marital status } & Single & $35(31.0)$ & $68(18.6)$ & $103(21.5)$ & 0.015 \\
\hline & Married & $78(69.0)$ & $296(80.9)$ & $374(78.1)$ & \\
\hline & Divorcee & $0(0.0)$ & $2(0.5)$ & $2(0.4)$ & \\
\hline \multirow[t]{3}{*}{ Habitat } & Rural & $4(3.5)$ & $21(5.7)$ & $25(5.2)$ & 0.001 \\
\hline & Urban & $108(95.6)$ & $299(81.7)$ & $407(85.0)$ & \\
\hline & Semi-urban & $1(0.9)$ & $46(12.6)$ & $47(9.8)$ & \\
\hline \multirow[t]{2}{*}{ Staying family } & No & $52(46.0)$ & $96(26.2)$ & $148(30.9)$ & $<0.001$ \\
\hline & Yes & $61(54.0)$ & $270(73.8)$ & $331(69.1)$ & \\
\hline \multirow[t]{2}{*}{ Pre-existing medical condition } & No & $97(85.8)$ & $261(71.3)$ & $358(74.7)$ & 0.002 \\
\hline & Yes & $16(14.2)$ & $105(28.7)$ & $121(25.3)$ & \\
\hline \multirow[t]{3}{*}{ Lifestyle } & Sedentary & $14(12.4)$ & $198(54.1)$ & $212(44.3)$ & $<0.001$ \\
\hline & Moderately active & $60(53.1)$ & $137(37.4)$ & $197(41.1)$ & \\
\hline & Hard labor & $39(34.5)$ & $31(8.5)$ & $70(14.6)$ & \\
\hline \multirow[t]{2}{*}{ Smoking habit } & Non-smoker & $105(92.9)$ & $324(88.5)$ & $429(89.6)$ & 0.182 \\
\hline & Smoker & $8(7.1)$ & $42(11.5)$ & $50(10.4)$ & \\
\hline \multirow[t]{3}{*}{ Workplace setting } & Primary & $6(5.3)$ & $53(14.5)$ & $59(12.3)$ & 0.001 \\
\hline & Secondary & $2(1.8)$ & $31(8.5)$ & $33(6.9)$ & \\
\hline & Tertiary & $105(92.9)$ & $282(77.0)$ & $387(80.8)$ & \\
\hline \multirow[t]{3}{*}{ COVID dedicated hospital } & No & $0(0.0)$ & $10(2.7)$ & $10(2.1)$ & $<0.001$ \\
\hline & Yes & $105(92.9)$ & $271(74.0)$ & $376(78.5)$ & \\
\hline & Worked in fever clinic instead & $4(3.5)$ & $68(18.6)$ & $72(15.0)$ & \\
\hline \multirow[t]{3}{*}{ Years of experience } & $<=5$ & $59(52.2)$ & $130(35.5)$ & $189(39.5)$ & 0.002 \\
\hline & $6-12$ & $37(32.7)$ & $188(51.4)$ & $225(47.0)$ & \\
\hline & $>12$ & $17(15.0)$ & $48(13.1)$ & $65(13.6)$ & \\
\hline \multirow[t]{2}{*}{ Duration of duty in COVID-19 ward } & Less than or equal 6 weeks & $47(41.6)$ & $190(51.9)$ & $237(49.5)$ & 0.055 \\
\hline & More than 6 weeks & $66(58.4)$ & $176(48.1)$ & $242(50.5)$ & \\
\hline
\end{tabular}


The overall prevalence of anxiety and depression, PTSD \& insomnia among all FHP in the study was $17.6 \%, 15.5 \%, 7.6 \%$ $\% 5.9 \%$ respectively. Medical doctors were more likely to develop anxiety symptoms $(\mathrm{OR}=4.19 ; 95 \% \mathrm{CI}=1.88-9.35$; p-value <0.001) and depression $(\mathrm{OR}=2.99 ; 95 \% \mathrm{CI}=1.40-6.42$; p-value 0.005) compared to allied health professionals. Doctors had also higher proportion of symptoms related to PTSD $(\mathrm{OR}=5.96 ; 95 \% \mathrm{CI}=1.41-25.11 ; \mathrm{p}$-value 0.015$)$ and insomnia $(\mathrm{OR}=9.22 ; 95 \% \mathrm{CI}=1.24-68.4 ; \mathrm{p}$-value 0.03$)$ than allied professionals (table-II).

Having Pre-existing medical conditions showed significant association (higher prevalence) of developing both anxiety
(28.9\% vs $12 \%$, p-value 0.000$)$ and depression $(22.3 \%$ v $10.3 \%$, p-value 0.001) compare to those who didn't have any. Those who had postgraduate degree (postgraduate vs graduate vs undergraduate: $25.7 \%$ vs $16.5 \%$ vs $1.9 \%$; p-value 0.001 ), over 12 years of experience ( $>12$ vs $6-12$ vs $<=5$ : $26.2 \%$ vs $16.9 \%$ vs $12.2 \%$; p-value 0.029 ) and working in secondary care settings (tertiary vs secondary vs primary: $14 \%$ vs $33.3 \%$ vs $22 \%$; p-value 0.007) had higher prevalence of developing anxiety symptoms. Working more than 6 weeks at Covid19 dedicated wards was implicated with higher prevalence of both PTSD (>6 weeks vs <6 weeks: $8.7 \%$ vs $3.8 \%$; p-value 0.028 ) and Insomnia ((>6 weeks vs <6 weeks: $7 \%$ vs $2.1 \%$; p-value 0.010$)$ (table-II).

Table-II

Prevalence of mental illness and comparison between doctors and allied health professionals

\begin{tabular}{|l|c|c|c|c|c|}
\hline $\begin{array}{l}\text { Outcome } \\
\text { variables }\end{array}$ & $\begin{array}{c}\text { Total } \\
\mathrm{n}(\%)\end{array}$ & $\begin{array}{c}\text { Prevalence } \\
\text { Medical } \\
\text { doctors } \mathrm{n}(\%)\end{array}$ & $\begin{array}{c}\text { Allied health } \\
\text { professionals } \mathrm{n}(\%)\end{array}$ & $\begin{array}{c}\text { Odds }(95 \% \\
\mathrm{CI})\end{array}$ \\
\hline Anxiety & $90(17.6)$ & $83(21.1)$ & $7(6.0)$ & $4.19(1.88,9.35)$ & $<0.001$ \\
\hline Depression & $79(15.5)$ & $71(18.0)$ & $8(6.8)$ & $2.99(1.40,6.42)$ & 0.005 \\
\hline PTSD & $39(7.6)$ & $37(9.4)$ & $2(1.7)$ & $5.96(1.41,25.11)$ & 0.015 \\
\hline Insomnia & $30(5.9)$ & $29(7.4)$ & $1(0.9)$ & $9.22(1.24,68.4)$ & 0.03 \\
\hline
\end{tabular}

\section{Table-III}

Logistic regression analysis of risk factors for mental health outcomes

\begin{tabular}{|c|c|c|c|c|c|}
\hline Outcome variables & $\begin{array}{l}\text { Variable } \\
\text { subcategories }\end{array}$ & $\begin{array}{c}\text { Unadjusted } \\
\text { Odds (95\% CI) }\end{array}$ & $\begin{array}{c}\text { P- } \\
\text { Value }\end{array}$ & $\begin{array}{c}\text { Adjusted } \\
\text { Odds }(95 \% \mathrm{CI})\end{array}$ & $\begin{array}{c}\text { P- } \\
\text { Value }\end{array}$ \\
\hline \multicolumn{6}{|l|}{ Anxiety } \\
\hline Educational Qualifications & Graduate & $5.91(1.406,24.831)$ & 0.015 & $4.35(1.011,18.730)$ & 0.048 \\
\hline (Reference: Undergraduate) & Postgraduate & $11.30(2.543,50.193)$ & 0.001 & $6.13(1.283,29.279)$ & 0.023 \\
\hline $\begin{array}{l}\text { Pre-existing medical condition } \\
\text { (Reference: No) }\end{array}$ & Yes & $3.23(2.01,5.18)$ & $<0.001$ & $2.85(1.711,4.761)$ & $<0.001$ \\
\hline Level working place & Secondary & $2.28(0.949,5.462)$ & 0.065 & $3.08(1.184,8.023)$ & 0.021 \\
\hline (Reference: Primary) & Tertiary & $0.64(0.335,1.231)$ & 0.182 & $0.75(0.339,1.669)$ & 0.483 \\
\hline COVID 19 dedicated hospital & Yes & $0.07(0.018,0.272)$ & $<0.001$ & $0.09(0.022,0.393)$ & 0.001 \\
\hline (Reference: No) & Worked in fever clinic instead & $0.11(0.028,0.469)$ & 0.003 & $0.10(0.021,0.429)$ & 0.002 \\
\hline Experience & $6-12$ & $1.22(0.729,2.028)$ & 0.453 & $1.47(0.820,2.640)$ & 0.196 \\
\hline (Reference: <6) & $>12$ & $2.02(1.043,3.926)$ & 0.037 & $1.64(0.705,3.811)$ & 0.251 \\
\hline \multicolumn{6}{|l|}{ Depression } \\
\hline Pre-existing medical condition & Yes & $2.29(1.391,3.774)$ & 0.001 & - & - \\
\hline \multicolumn{6}{|l|}{ (Reference: No) } \\
\hline \multicolumn{6}{|l|}{ PTSD } \\
\hline $\begin{array}{l}\text { Duration of COVID } 19 \text { duty } \\
\text { (Reference: No) }\end{array}$ & More than 6 weeks & $2.83(1.347,5932)$ & 0.006 & - & - \\
\hline \multicolumn{6}{|l|}{ Insomnia } \\
\hline $\begin{array}{l}\text { Duration of COVID } 19 \text { duty } \\
\text { (Reference: No) }\end{array}$ & More than 6 weeks & $2.63(1.147,6.017)$ & 0.022 & - & - \\
\hline
\end{tabular}


By adjusting the confounders using stepwise logistic regression, the study found that having a postgraduate degree (adjusted $\mathrm{OR}=6.13 ; 95 \% \mathrm{CI}=1.283-29.279 ; \mathrm{p}$-value 0.023 ) compared to undergraduate. Working in a secondary care setting (adjusted $\mathrm{OR}=3.08$; 95\% CI= 1.184-8.023; p-value 0.021) was also a significant risk factor for developing anxiety symptoms compared to primary care setting. Having pre-existing medical condition was a risk factors for both anxiety (adjusted $\mathrm{OR}=2.85 ; 95 \% \mathrm{CI}=1.711-4.761$; p-value $<0.001$ ) and depression (unadjusted $\mathrm{OR}=2.29$; 95\% CI= 1.391-3.774; p-value 0.001). Interestingly, this study revealed working in a Covid19 dedicated ward as a protective factor for anxiety (adjusted $\mathrm{OR}=0.07 ; 95 \% \mathrm{CI}=0.018-0.272$; p-value $<0.001$ ) compare to other settings. Working more than 6 weeks in COVID19 dedicated ward had been a significant risk factor for both PTSD (unadjusted $\mathrm{OR}=2.83$; 95\% CI= 1.347-5.932; p-value 0.006). and Insomnia (unadjusted $\mathrm{OR}=2.63 ; 95 \% \mathrm{CI}=$ 1.147-6.017; p-value 0.022) (table-III).

\section{Discussion}

To our knowledge, this was the first study to examine the mental health impact of the Covid-19 pandemic among frontline health care workers just after the early phase of the pandemic in Bangladesh. This study was conducted three months after the diagnosis of the first case in Bangladesh on 8 March 2020 at the middle stage of the first wave of the pandemic. ${ }^{14}$ This study revealed the prevalence of anxiety (17.6\%), depression (15.5\%), and insomnia (5.9\%) symptoms among health workers was higher compare to the pre-pandemic general population as reported in the most recent national mental health survey in Bangladesh conducted by National Institute of Mental Health in 2018-201915 where the lifetime prevalence for anxiety, depression, and insomnia was reported as $4.5 \%(95 \% \mathrm{CI}=3.8-5.3), 6.7 \%(95 \% \mathrm{CI}=5.8-7.6)$ and $0.9 \%(95 \% \mathrm{CI}=0.4-0.9)$ respectively. Although there is no data on the lifetime prevalence of PTSD among the Bangladeshi population, the prevalence rate for PTSD (7.6\%) reported in this study is higher compare to the prevalence of the same $(2.1 \%)$ reported in the world mental health survey. ${ }^{16}$ The prevalence of anxiety and depression reported in this study are largely similar with a pooled prevalence of anxiety (15.15\%; 95\% CI= 12.29-18.54) and depression (15.97\%; 95\% $\mathrm{CI}=13.24-19.13)$ reported in a meta-analysis of global studies during Covid19 pandemic on general population; however, the prevalence of PTSD and insomnia symptoms of this study appeared as far less compared with the same meta-analysis where prevalence rate for PTSD and insomnia were reported as $21.94 \%(95 \% \mathrm{CI}=9.37-43.31)$ and $23.87 \%$ (95\% CI $=15.74-$ 34.48 ) respectively. ${ }^{17}$ The pooled prevalence of anxiety $(43.6 \%$; $95 \% \mathrm{CI}=33.1-54.5)$ and depression $(29.9 \%$; $95 \% \mathrm{CI}=23.9-36.2)$ among health workers reported in a meta-analysis of studies conducted in South Asian countries were also very significantly high compare to this study. ${ }^{18}$ A similar very high pattern of prevalence of anxiety and depression was reported in Chinese studies conducted in the earlier stage of pandemic. ${ }^{19,20}$ Facing a pandemic situation or a natural disaster, the psychological response of front-line health care workers might be complex and based on many factors. Lack of prevention and control knowledge about the pandemic. ${ }^{21}$ rumors in social media, ${ }^{22,23,24}$ underprepared service structure, ${ }^{25}$ lack of personal protective equipment (PPE), 26,27 high risk of exposure, and the chance of spreading to the family, ${ }^{28}$ loss and grief , ${ }^{29}$ financial worries and over-exhaustion, 30 all can contribute to developing psychological issues-particularly in early stage which may explain the high prevalence of mental illness among front-line health workers in early studies. When this study was conducted (June to August 2020), Bangladeshi health services became more organized, better knowledge about the pandemic, and relatively easy availability of PPE may have increased resilience and improved coping skills of the front-line workers. Relative desensitization due to three month's exposure to the pandemic, having the experience of frequent natural calamities in Bangladesh, and timely effective measures taken by the Bangladeshi authority to contain the pandemic, may have contributed to higher baseline resilience. All of these factors may also explain the relatively lower prevalence of mental illness compared to those early studies conducted in other parts of the world. Unlike many other studies, we excluded participants with a pre-pandemic history of mental illness which may be another important factor implicating on findings of this study.

This study showed that medical doctors had higher odds of experiencing anxiety, depression, PTSD, and insomnia than nurses and other allied health professions.

This finding is consistent with the earlier reports from other studies $^{31,32}$ but inconsistent with the finding of several other studies where nurses had a higher prevalence ${ }^{33,34}$ In those studies, the reason was attributed to the higher amount of time spent by nurses in direct patient care than doctors. A higher number of doctor's participation $(76 \%)$ in our study may have impacted the findings of our study.

In this study, several sociodemographic and workplace factors showed a significant association with increased prevalence of anxiety, depression, PTSD, and insomnia symptoms. Having underlying medication conditions among health care workers reported as independently associated with both depression and anxiety. Postgraduate or graduate participants with over 6 years of experience would most likely be senior doctors who showed higher odds of experiencing anxiety symptoms. Working more than six weeks in Covid-19 dedicated wards was an independent risk factor for developing both insomnia and PTSD symptoms. These findings are particularly important as these will underpin the local policy development to provide timely targeted interventions for these vulnerable groups which will improve the mental health of frontline health 
workers and overall patient care. Ensuring a safe working environment, access to necessary information and equipment, realistic workload, targeted support, and interventions for the most vulnerable would be a necessity for the optimal mental health and wellbeing of frontline health workers. ${ }^{35}$

This study has several limitations that would need to be acknowledged. Firstly, this cross-sectional study design will only inform the 'snapshot'. The allostatic load of the pandemic to mental health disorders needs to be evaluated using a longitudinal study design. Secondly, there might have been the introduction of selection bias as health care workers who had internet access to complete Google Form were included. Allied health care professionals, Older and senior health care workers were disproportionately low in numbers might have skewed the data. Unlike many other studies, we have tried to minimize response bias by interviewing the participants rather than solely relying on self-reported tools. Thirdly, the study tools (PHQ-4, PC-PTSD, ISI) were screening tools to identify likely case and not validated in Bengali but all participants use English as a second language hence the interviewer didn't face any significant difficulty. Fourthly, this study only included a limited number of factors as independent variables and only four mental conditions as outcome variables. The impact of other variables might have a confounding effect.

\section{Conclusion}

This study demonstrated a high burden of anxiety, depression, PTSD, and insomnia symptoms among front-line health care workers in Bangladesh during the COVID-19 pandemic as well as some significant risk factors for them. Physical and mental health protection of frontline health care workers would be of utmost importance to provide effective control measures for pandemic and associated patient care. Effective development of policy and implementation of interventions particularly targeting the vulnerable groups are essential to protect and promote the mental health and well-being of frontline health care workers both locally and globally.

\section{Ethics}

The study was approved by the Institutional Review Board of Bangabandhu Sheikh Mujib Medical University (BSMMU/ 2020/6238 issued on 3rd June 2020).

Acknowledgment: The authors would like to acknowledge all the frontline health workers who participated in the study.

\section{Authors' contribution}

SA and MSA conceived the concept and design of the study. SA, MSA, RK, MMH prepared the data collection form. MMH programmed the forms in Google forms. MSA, RK, MMH, AK, HS, FF, and MH implemented the study. SA, MSA, and MKH conducted data analysis. SA and MSA wrote the first draft, which underwent substantial revision based on the inputs from all other authors. SA and MSA supervised the whole study process. All of the authors have read, reviewed, and endorsed the final version of the manuscript.

\section{Conflict of interest}

Authors have no conflict of interests associated with this paper.

\section{Financial disclosure}

The author(s) disclosed receipt of the financial support for the research from the special COVID-19 University Research Grant, Bangabandhu Sheikh Mujib Medical University (BSMMU), Dhaka, Bangladesh (grant number: BSMMU/ 2020/6238)

\section{References}

1. Li Q, Guan X, Wu P, Wang X, Zhou L, Tong Y, Ren R, Leung KS, Lau EH, Wong JY, Xing X. Early transmission dynamics in Wuhan, China, of novel coronavirus-infected pneumonia. New England journal of medicine. 2020 Jan 29.

2. Coronavirus disease (COVID-19) - World Health Organization. https://www.who.int/emergencies/diseases/ novel-coronavirus-2019. Accessed 7 February 2021.

3. Wu P, Fang Y, Guan Z, Fan B, Kong J, Yao Z, Liu X, Fuller CJ, Susser E, Lu J, Hoven CW. The psychological impact of the SARS epidemic on hospital employees in China: exposure, risk perception, and altruistic acceptance of risk. The Canadian Journal of Psychiatry. 2009 May;54(5): 302-11.

4. Sim MR. The COVID-19 pandemic: major risks to healthcare and other workers on the front line. Occupational and environmental medicine 77, 281-282.

5. Schwartz J, King CC, Yen MY. Protecting healthcare workers during the coronavirus disease 2019 (COVID-19) outbreak: lessons from Taiwan's severe acute respiratory syndrome response. Clinical Infectious Diseases. 2020 Jul 28;71(15):858-60.

6. Sim MR. The COVID-19 pandemic: major risks to healthcare and other workers on the front line.Occupational and environmental medicine 77, 281-282. 
7. Tan BY, Chew NW, Lee GK, Jing M, Goh Y, Yeo LL, Zhang K, Chin HK, Ahmad A, Khan FA, Shanmugam GN. Psychological impact of the COVID-19 pandemic on health care workers in Singapore. Annals of internal medicine. 2020 Aug 18;173(4):317-20.

8. Zhang WR, Wang K, Yin L, Zhao WF, Xue Q, Peng M, Min $B Q$, Tian Q, Leng HX, Du JL, Chang H. Mental health and psychosocial problems of medical health workers during the COVID-19 epidemic in China. Psychotherapy and psychosomatics. 2020;89(4):242-50.

9. Schwartz J, King CC, Yen MY. Protecting healthcare workers during the coronavirus disease 2019 (COVID-19) outbreak: lessons from Taiwan's severe acute respiratory syndrome response. Clinical Infectious Diseases. 2020 Jul 28;71(15):858-60.

10. Xiang YT, Yang $Y$, Li W, Zhang L, Zhang Q, Cheung T, Ng $\mathrm{CH}$. Timely mental health care for the 2019 novel coronavirus outbreak is urgently needed. The Lancet Psychiatry. 2020 Mar 1;7(3):228-9.

11. Kroenke K, Spitzer RL, Williams JB, Löwe B. An ultra-brief screening scale for anxiety and depression: the PHQ-4. Psychosomatics. 2009 Nov 1;50(6):613-21.

12. Prins A, Bovin MJ, Smolenski DJ, Marx BP, Kimerling R, Jenkins-Guarnieri MA, Kaloupek DG, Schnurr PP, Kaiser AP, Leyva YE, Tiet QQ. The primary care PTSD screen for DSM-5 (PC-PTSD-5): development and evaluation within a veteran primary care sample. Journal of general internal medicine. 2016 Oct;31(10):1206-11.

13. Gagnon C, Bélanger L, Ivers H, Morin CM. Validation of the Insomnia Severity Index in primary care. The Journal of the American Board of Family Medicine. 2013 Nov 1;26(6):701-10.

14. Sharif N, Dey SK. Phylogenetic and whole genome analysis of first seven SARS-CoV-2 isolates in Bangladesh. Future Virology. 2020 Nov;15(11):735-46.

15. National Insititute of Mental Health..National Mental Health Survey in Bangladesh 2018-2019. http://nimh.gov.bd/news-events/

16. Koenen KC, Ratanatharathorn A, Ng L, McLaughlin KA, Bromet EJ, Stein DJ, Karam EG, Ruscio AM, Benjet C, Scott $\mathrm{K}$, Atwoli L. Posttraumatic stress disorder in the world mental health surveys. Psychological medicine. 2017 Oct;47(13):2260-74.

17. CénatJM, Blais-Rochette C, Kokou-Kpolou CK, Noorishad PG, Mukunzi JN, McIntee SE, Dalexis RD, Goulet MA, Labelle P. Prevalence of symptoms of depression, anxiety, insomnia, posttraumatic stress disorder, and psychological distress among populations affected by the COVID-19 pandemic: A systematic review and meta-analysis. Psychiatry research. 2020 Nov 26:113599.
18. Hossain MM, Rahman M, Trisha NF, Tasnim S, Nuzhath T, Hasan NT, Clark H, Das A, McKyer EL, Ahmed HU, Ma P. Prevalence of anxiety and depression in South Asia during COVID-19: A systematic review and meta-analysis.

19. Lai J, Ma S, Wang Y, Cai Z, Hu J, Wei N, Wu J, Du H, Chen T, Li R, Tan H. Factors associated with mental health outcomes among health care workers exposed to coronavirus disease 2019. JAMA network open. 2020 Mar 2;3(3):e203976-.

20. Zhang WR, Wang K, Yin L, Zhao WF, Xue Q, Peng M, Min $B Q$, Tian Q, Leng HX, Du JL, Chang H. Mental health and psychosocial problems of medical health workers during the COVID-19 epidemic in China. Psychotherapy and psychosomatics. 2020;89(4):242-50.

21. Liu Q, Luo D, Haase JE, Guo Q, Wang XQ, Liu S, Xia L, Liu $\mathrm{Z}$, Yang J, Yang BX. The experiences of health-care providers during the COVID-19 crisis in China: a qualitative study. The Lancet Global Health. 2020 Jun 1;8(6):e790-8.

22. Gao J, Zheng P, Jia Y, Chen H, Mao Y, Chen S, Wang Y, Fu $\mathrm{H}$, Dai J. Mental health problems and social media exposure during COVID-19 outbreak. Plos one. 2020 Apr 16;15(4):e0231924.

23. Hossain MT, Ahammed B, Chanda SK, Jahan N, Ela MZ, Islam MN. Social and electronic media exposure and generalized anxiety disorder among people during COVID-19 outbreak in Bangladesh: A preliminary observation. Plos one. 2020 Sep 11;15(9):e0238974.

24. Tasnim S, Hossain MM, Mazumder H. Impact of rumors and misinformation on COVID-19 in social media. Journal of preventive medicine and public health. 2020 Apr 2;53(3):171-4.

25. Chen Q, Liang M, Li Y, Guo J, Fei D, Wang L, He L, Sheng C, Cai Y, Li X, Wang J. Mental health care for medical staff in China during the COVID-19 outbreak. The Lancet Psychiatry. 2020 Apr 1;7(4):e15-6.

26. Schwartz J, King CC, Yen MY. Protecting healthcare workers during the coronavirus disease 2019 (COVID-19) outbreak: lessons from Taiwan's severe acute respiratory syndrome response. Clinical Infectious Diseases. 2020 Jul 28;71(15):858-60.

27. Sim MR. The COVID-19 pandemic: major risks to healthcare and other workers on the front line.Occupational and environmental medicine 77, 281-282.

28. Kang L, Ma S, Chen M, Yang J, Wang Y, Li R, Yao L, Bai H, Cai Z, Yang BX, Hu S. Impact on mental health and perceptions of psychological care among medical and nursing staff in Wuhan during the 2019 novel coronavirus disease outbreak: A cross-sectional study. Brain, behavior, and immunity. 2020 Jul 1;87:11-7. 
29. Theorell T. Evaluating life events and chronic stressors in relation to health: stressors and health in clinical work. The psychosomatic assessment. 2012;32:58-71.

30. Kang L, Ma S, Chen M, Yang J, Wang Y, Li R, Yao L, Bai H, Cai Z, Yang BX, Hu S. Impact on mental health and perceptions of psychological care among medical and nursing staff in Wuhan during the 2019 novel coronavirus disease outbreak: A cross-sectional study. Brain, behavior, and immunity. $2020 \mathrm{Jul}$ 1;87:11-7

31. Elkholy H, Tawfik F, Ibrahim I, Salah El-din W, Sabry M, Mohammed S, Hamza M, Alaa M, Fawzy AZ, Ashmawy $\mathrm{R}$, Sayed M. Mental health of frontline healthcare workers exposed to COVID-19 in Egypt: A call for action. International Journal of Social Psychiatry. 2020 Sep 24:0020764020960192.

32. Zhang WR, Wang K, Yin L, Zhao WF, Xue Q, Peng M, Min BQ, Tian Q, Leng HX, Du JL, Chang H. Mental health and psychosocial problems of medical health workers during the COVID-19 epidemic in China. Psychotherapy and psychosomatics. 2020;89(4):242-50.

33. Maunder RG, Lancee WJ, Rourke S, Hunter JJ, Goldbloom D, Balderson K, Petryshen P, Steinberg R, Wasylenki D, Koh D, Fones CS. Factors associated with the psychological impact of severe acute respiratory syndrome on nurses and other hospital workers in Toronto. Psychosomatic medicine. 2004 Nov 1;66(6): 938-42.

34. Khanal P, Devkota N, Dahal M, Paudel K, Joshi D. Mental health impacts among health workers during COVID-19 in a low resource setting: a cross-sectional survey from Nepal. Globalization and health. 2020 Dec;16(1):1-2.

35. Schwartz J, King CC, Yen MY. Protecting healthcare workers during the coronavirus disease 2019 (COVID-19) outbreak: lessons from Taiwan's severe acute respiratory syndrome response. Clinical Infectious Diseases. 2020 Jul 28;71(15):858-60. 